Tesis. Año 13, 12(14), 2019, 27-44

\title{
Ficcionalidad y subalternidad en el mundo representado de Sarita Colonia viene volando"
}

\author{
Jamess Lozano Mejía \\ lozanomejia@hotmail.com
}

\section{Resumen}

Proponemos una lectura que considere a Sarita Colonia viene volando (1990) una historia que tiene su origen o pretexto en la cultura no oficial (subalterna), representada por su protagonista y sus fieles. La representación de la subalternidad en la novela establece la presencia de un discurso crítico al sistema imperante.

Por otro lado, es menester realizar un análisis ficcional de la novela porque se le ha leído alternativamente como un relato testimonial-antropológico; como una biografía resemantizada de Sarita Colonia Zambrano. En ambas lecturas está primando el aspecto sociológico y se está obviando toda influencia literaria. Es decir, se está dejando de lado todo el valor simbólico de la ficción.

Palabras clave: mundo posible, subalternidad, realismo maravilloso, ideología.

\begin{abstract}
We propose a reading that considers Sarita Colonia comes flying (1990) a story that has its origin or pretext in the unofficial (subaltern) culture, represented by its protagonist and its faithful. The representation of subalternity in the novel establishes the presence of a critical discourse to the prevailing system.

On the other hand, it is necessary to make a fictional analysis of the novel because it has been read alternatively as a testimonial - anthropological story; like a resemantized biography of Sarita Colonia Zambrano. In both readings, the sociological aspect is prevailing and all literary influence is being ignored. That is, all the symbolic value of fiction is being left aside.
\end{abstract}

Keywords: possible world, subalternity, marvelous realism, ideology. 


\section{Ficcionalidad y subalternidad en el mundo representado de Sarita Colonia viene volaredo}

\section{Introducción}

La crítica literaria se ha centrado, casi exclusivamente, en destacar que Sarita Colonia viene volando (1990), de Eduardo González Viaña, es un relato testimonial donde predomina la oralidad y recalca que es una biografía resemantizada de Sarita Colonia; es decir, estas resultan ser valoraciones sociológicas donde se ha olvidado de algo fundamental: estamos ante un texto ficcional. Por ello, en este artículo, proponemos una reflexión del mundo posible a partir del cual demostramos que la novela no es una biografía de Sarita Colonia, pues la protagonista está totalmente despragmatizada de su prototipo real. Para nosotros, Sarita Colonia viene volando, desde el inicio hasta el final, presenta elementos propios del realismo maravilloso. Los acontecimientos que presenciamos en la novela son extraordinarios, la vida y la muerte no tienen fronteras. A partir de este análisis ficcional nos damos cuenta de que estamos frente a un texto muy complejo, donde se plantean una serie de temas: migración, subalternidad, violencia política, intertextualidad, cosmovisión andina, etc. Nosotros hemos abordado la subalternidad de la novela, donde damos cuenta que esta denuncia el sistema imperante: la marginación, la desigualdad, la mala distribución de la riqueza, la pésima educación e injusticia para el pobre.

\section{El mundo posible de Sarita Colonia viene volando}

Romina Gatti (2009) afirma que Sarita Colonia viene volando, aparte de ser una novela es también una especie de biografía sacra (género que se produjo durante la Edad Media y que aún es parte de la tradición del mundo occidental). A lo largo de su análisis presenta coincidencias y divergencias entre la biografía sacra y lo desarrollado por Eduardo González Viaña.

La primera coincidencia que la investigadora señala es la siguiente: "tanto el género biográfico sacro como el texto ficcional tienen como materia la creencia 
surgida en un grupo humano, en una comunidad de práctica" (Gatti, 2009, p. 3). Es decir, la biografía sacra recrea la vida de un determinado santo (no necesariamente canonizado). Lo mismo ha hecho Eduardo González Viaña, desde la perspectiva de Gatti, con la vida de Sarita Colonia (tenida como santa por una comunidad, aunque todavía no ha sido aceptada como tal por la Iglesia). En segundo lugar, Gatti nos dice: "alrededor del venerable surgía de forma espontánea y oral una serie de relatos acerca de sus peripecias en vida. Los religiosos preocupados por la difusión del culto se encargaban de recopilarlos y conceptualizarlos [...]. Ha de verse que, en la novela, el narrador se identifica como interesado en tomar las historias que circulan acerca de la vida y milagros de la joven para elaborar un texto literario" (Gatti, 2009, p. 4).

En las dos coincidencias que presenta Romina Gatti nos da a entender que Sarita Colonia viene volando es un texto antropológico porque el autor ha realizado un trabajo de campo, al igual que lo hacían los religiosos medievales para reconstruir la vida de algún santo. No obstante, debemos decir que no es prioridad central del autor reconstruir la vida de Sarita Colonia Zambrano, porque la novela no es una biografía. Es cierto, la protagonista de nuestra historia tiene su prototipo en el mundo real. La pregunta que nos cabe formular es ¿cómo está ligado el personaje ficcional Sarita Colonia con su prototipo real en el relato? Aplicando los postulados de Dolezel (1999), en este caso el personaje ficcional está ligado con su prototipo real por una identidad de intermundos ${ }^{2}$. Es decir, comparten el mismo nombre, pero no significa que el personaje se comporte igual que su prototipo real, porque si esto sucediera ya no estaríamos frente a una ficción, sino ante una biografía. Iser (1987) al respecto nos dice que los objetos empíricos tomados de la realidad en el texto son transformados en otra cosa. Lo que hace un proceso complejo de entendimiento para el lector, pues la ficción transforma todo, despragmatiza al objeto. Por ello, afirma, en lugar de comparar si el texto describe el objeto pretendido correcta o falsamente, adecuada o inadecuadamente, etc.; el lector debe constituir frecuentemente el "objeto" en contra del mundo habitual del objeto que invoca el texto. En otras palabras, la referencialidad externa es solo para darle un efecto de verdad al relato ${ }^{3}$. Con esta estrategia narrativa, Eduardo González Viaña está trasgrediendo el género biográfico, estableciendo una crítica al mismo, relativizando su estatuto, contrariamente a lo que plantea Gatti.

Dolezel señala que la semántica de los mundos posibles nos hace darnos cuenta de que el material que procede del mundo real tiene que sufrir una transformación sustancial en la frontera entre los dos mundos. Él afirma: "A causa de la soberanía ontológica de los mundos ficcionales, las entidades del mundo real tienen que ser convertidas en posibles no reales con todas las consecuencias ontológicas, lógicas y semánticas que esta transformación acarrea" (Dolezel, 1999, p. 43). La Sarita Colonia que vivió en el mundo real tuvo una 
existencia típica o "normal" como la de cualquier ser humano pobre. Se sabe que fue empleada del hogar al servicio de una señora italiana. Con respecto a su muerte prematura resultan poco menos que normales datos estadísticos ${ }^{4}$. En cambio, la Sarita Colonia de nuestra novela en estudio es totalmente distinta: tiene poderes sobrenaturales, conversa con Dios y le suceden cosas extraordinarias. Por ejemplo, en la casa de la señora italiana ella conversaba con las flores, hacía milagros y le ocurrían acontecimientos extraordinarios: los ángeles bajaban del cielo cuando ella rezaba el rosario con su patrona. Leamos una parte de la escena referida.

La vio conversar con las flores, y tan solo se le antojó que era un tanto parlanchina. Advirtió que curaba a los enfermos y solía devolver la alegría a los desamparados, y sin criticarla pensó que acaso era demasiado sociable, y en medio de las interminables jaculatorias del santísimo rosario presintió que Sarita estaba acompañada o más bien atraía lo invisible por el hecho de que los ángeles, los querubines y los santos no se hicieran demasiado evidentes: la casa era grande, y también el corazón, pero no lo eran tanto como para admitir tantas presencias celestiales. (p. 210)

Por último, Gatti nos dice que para los medievales el santo jugaba un rol central como facilitador de bienestar terrestre e iluminador del camino hacia la salvación. Ella explica: "Al analizar la construcción de la figura sacra que se constituye como protagonista del texto, es inevitable notar que también ella es exaltada porque se la considera capaz de influir significativa y positivamente en el día a día de sus seguidores" (Gatti, 2009, p. 5). En esta coincidencia, Gatti vuelve a asumir la novela como un texto biográfico- antropológico en donde compara la conducta de los creyentes medievales con los fieles de Sarita Colonia, sin darle ninguna importancia a que se trata de un texto ficcional. Una biografía recrea o representa la vida de una persona real que tiene una existencia independiente si se la representa o no en un texto. En cambio, la vida de los personajes de una ficción no tienen existencias independientes. Ellos existen cuando un autor los ha creado y junto a ellos el mundo en el que van a habitar. La Sarita Colonia Zambrano que parte de su vida vivió en el Callao, tiene una existencia independiente, al margen que su biografía sea polémica y contradictoria. Y si nadie hubiera escrito nada sobre ella, igual siguiría existiendo. Sin embargo, la Sarita Colonia de nuestra novela no tiene existencia independiente, ella llegó a existir porque Eduardo González Viaña creó su mundo posible, lugar en donde ella habita. Y lo más importante, un texto ficcional es más complejo que una biografía; en Sarita Colonia viene volando no podemos limitar todo su potencial comunicativo ficcional a un estudio sociológico que compara conductas de fe entre fieles medievales y los de Sarita Colonia. La novela de- 
sarrolla temas mucho más complejos: realismo maravilloso, violencia política, subalternidad, migración, etc.

Romina Gatti, como se mencionó al inicio, no solo señala coincidencias entre el género biográfico y la novela, sino también divergencias. Una de ellas se refiere a la Voz. Ella afirma: "en las biografías sacras solo existe un narrador, en cambio en la novela existen una multiplicidad de voces que se subordinan a un narrador protagonista como una orquesta lo hace con su director" (Gatti, 2009 , p. 7). En este tema llega a la siguiente conclusión: "en la novela se elabora la participación de un narrador colectivo que construye una sola verdad, lo que constituye una primera evidencia de su función apelativa" (Gatti, 2009, p. 9). Es verdad que en la historia hay multiplicidad de voces, pero ninguna se subordina a la voz del narrador o la de otro personaje, cada quien tiene su propia verdad, es decir, en la novela no existe la verdad absoluta porque no estamos frente a una biografía. Nosotros compartimos el juicio de Alicia Andreu (1999), quien nos dice que los narradores se contradicen y que no todos son narradores antropomorfos. Ella asevera: "algunos de ellos proceden de las abejas, por ejemplo, o de las palmeras de Huaraz, o de flores como la azucena. Lo que también se puede afirmar es que cada una de estas voces narrativas se encuentra en control de su propio relato; cada una de ellas contiene su propia verdad" (Andreu, 1999, p. 35).

Tampoco compartimos con Romina Gatti cuando afirma que Eduardo González Viaña es igual al "hablante o emisor no ficcional que conduce la narración" (Gatti, 2009, p. 7). Ella confunde narrador con autor. El autor es una persona real que vive en el mundo fáctico, el narrador es un personaje más creado por el autor, por tanto, no son iguales. Nuevamente la investigadora está asumiendo que Eduardo González Viaña ha escrito una biografía, no una novela. Con respecto a este punto compartimos la crítica de José Miguel Oviedo $(1971)^{5}$, quien nos dice que Eduardo González Viaña acostumbra a convertirse en un personaje más en sus obras, él señala: "la manera de mezclar la realidad con la ficción, de ser él mismo un personaje más en sus obras es un caso bastante singular en la narrativa peruana, que lo diferencia de Miguel Gutiérrez, Alfredo Bryce Echenique" (Oviedo, 1971, p. 88).

Alicia Andreu nos dice que, en Sarita Colonia Viene Volando, Eduardo González Viaña asume el rol de etnógrafo, de recolector de relatos orales, pero hace una distinción con los antropólogos tradicionales, los cuales manipulan la palabra oral para la satisfacción de sus propios intereses, en muchos casos ideológicos. Ella señala: "el 'autor' de Sarita Colonia viene volando le brinda a los autores de la palabra oral una posición tan privilegiada como la suya. Conviene añadir que con esta nueva redefinición de autor, González Viaña se auto-representa como un autor más dentro de la multiplicidad de autores que contribuyen a la formación de la novela" (Andreu, 1999, p. 39). A partir de esta cita podemos 
ver que Andreu se da cuenta de que el narrador oficial es distinto al autor; sin embargo, está asumiendo que los testimonios son copiados tal cual, no repara en que estos al ingresar al campo de referencia interno de la historia se despragmatizan; no se trata solo de copiar, porque si no estaríamos enteramente frente a una crónica y no ante un texto ficcional. Recordemos que la ficción crea mundos posibles que vienen a constituir un reino aparte de la realidad con sus propias reglas y naturaleza.

\section{Realismo maravilloso en Sarita Colonia viene volando}

Ricardo González Vigil (1984) ${ }^{6}$ nos dice: "la narrativa de Eduardo González Viaña concilia lo fantástico con lo real maravilloso, que vienen a ser modos diversos de superar los cánones realistas y arañar el misterio" (González, 1984, p. 20). Con esta valoración nosotros coincidimos porque efectivamente en Sarita Colonia viene volando existen desde el inicio hasta el final de la novela elementos propios del realismo maravilloso. La protagonista ha resucitado después de treinta años de haber estado muerta y tiene el poder de soñar lo que ella desea, es así que dirige su sueño al Huaraz de su infancia para reencontrarse con su familia y con ella misma. Leamos la siguiente escena en donde se evidencia esto.

A lo mejor, no se hizo más preguntas inútiles, y prefirió enterarse de qué poderes dispone la gente que despierta después de haber muerto durante treinta años, y descubrió que también se puede soñar, y, lo que es más asombroso, conducir los sueños, o más bien determinar qué sueño se quiere vivir de nuevo, y en qué época y lugar uno prefiere que sus sueños otra vez caminen.

Y Sarita, por supuesto, decidió recordar y volver a vivir el tiempo de su infancia en Huaraz. Quería ver a sus hermanos. También ansiaba reencontrar a sus padres con el rostro feliz que tenían antes de emigrar de su tierra. Y por fin, quería verse ella misma: tanto tiempo había pasado desde su muerte que ya se estaba olvidando de su cara. (p. 35)

José Antonio Bravo (2011) nos dice que, en el realismo maravilloso, los acontecimientos vinculados con los resucitados son sucesos extraordinarios; la vida y la muerte no tienen fronteras. Estas características se notan claramente en la escena que acabamos de citar: la resurrección de la protagonista es un hecho extraordinario, la frontera entre la muerte y la vida se ha anulado.

José Antonio Bravo, también afirma lo siguiente: "en el realismo maravilloso el paisaje, la geografía, los lugares, los ambientes exteriores e interiores, son extraños, misteriosos, remotos, extraordinarios, exagerados" (Bravo, 2011, p. 119). En la novela, desde el principio hasta el fin se evidencian estas características. Por ejemplo, una profesora enseñó a leer y a escribir a su hija Hortensia, quien había muerto a los diez días de nacida. Cuando la niña cumplió diez 
años, se comunicó con su madre desde el más allá. Notamos en esta escena que el ambiente de la hija es remoto, totalmente extraordinario. Por el otro lado, el ambiente de la madre también es extraño, misterioso. Leamos un fragmento de la escena.

Y seguro que esto fue lo que conversamos: "mamita, soy yo, Hortensia". "Claro que lo sé, si ya te he sentido, querida hijita muerta, mi chiquitita, si siempre he estado pensando en ti, en lo sola que te sentirías". "Sola sí, pero no me digas chiquitita porque ya no soy una niña. Recuerda que ya tengo diez años, y recuerda que me enseñaste a leer y escribir”. (p. 87)

Luis Alberto Sánchez (1981) es muy claro al señalar: "Eduardo González Viaña es un prosista lírico anegado de sueños oníricos, preocupado por una expresión al par ceñida y vaga. Lo primero en cuanto a decir solo lo que quiere; lo segundo por el empeño de dejar que las imaginaciones y los sueños fluyan de suyo, sin refugiarse en una lógica impuesta y contradictoria" (Sánchez, 1981, p. 2172). Con estas reflexiones estamos de acuerdo porque nuestro objeto de estudio está compuesto por una prosa poética; Juan Burro, el Embajador de Quiquijana y Pochi Marambio cuentan la vida de Sarita a ritmo de versos plasmados en poesía, en canciones. En las historias que nos cuentan notamos que los personajes están sumergidos en un total realismo maravilloso, los sueños oníricos fluyen. Por ejemplo, el Embajador de Quiquijana nos cuenta que don Amadeo Colonia llegó a tener un romance muy fuerte con una mujer casada, al igual que él, de nombre Bernarda; pero lo extraño de este idilio era que se dio únicamente en sueños, la mujer ingresaba en los sueños de don Amadeo. Leamos una parte de esta historia.

Asegura que Amadeo se daba citas con la mujer de sus sueños y que aquella dejaba de aparecerse algunas noches y a veces semanas enteras. Pero no era desamor aquello: ocurría únicamente que ella era también comprometida. Amadeo le propuso una noche que se fugaran juntos, pero Bernarda le respondió que iba a pensarlo. Esto los distanció algo más de un mes hasta que por fin ella volvió a los sueños de Amadeo para responderle que ya estaba decidida al todo por el todo.

En ese momento, el soñador ya tenía dudas: le dolía abandonar a su familia. Bernarda le dijo que no estaría esperándolo siempre, que mejor quedaran como amigos. Así fue. (p. 178)

José Miguel Oviedo (1971) resalta que en la obra de nuestro escritor prevalece la voluntad de enmascarar la realidad o desubicarnos respecto a ella, el crítico menciona: "Presentimos la existencia de un cielo y un infierno, de una zona segura y una zona amenazante, pero no sabemos bien de qué lado estamos. Todo es ambiguo, todo está medio vivo y medio muerto" (Oviedo, 1971, 
p. 87). En Sarita Colonia viene volando, la ambigüedad entre la vida y la muerte está muy presente - elemento muy común en el realismo maravilloso, tal como ya lo mencionó José Bravo - . Juan Burro nos cuenta que don Amadeo Colonia, cuando se estaba viniendo para la capital, conversó con un arriero muerto que le sirvió de guía durante un trayecto de su camino. Leamos un fragmento de la escena.

- Entonces, ¿̇ú estás muerto? - Seguro que eso fue lo que le preguntó al arriero. Y eso debe haber sido porque solo los muertos pueden saber si uno es padre de una santita.

- Muerto sí, pero no sepultado - supongo que respondió el arriero, quien probablemente estaba diciendo la verdad porque los arrieros muertos suelen quedarse en los caminos cuando no se les da cristina sepultura, y por esos andurriales se quedan, a veces para guiar a los viajeros, a veces para embaucarlos. (p. 67)

Retomando las reflexiones de José Antonio Bravo, él nos dice: "en el paisaje de lo real maravilloso puede haber también personajes extraños, misteriosos" (Bravo, 2011, p. 33). En la novela no solo existen personajes humanos, sino también otros seres que cuentan la historia de Sarita Colonia; como por ejemplo las palmeras de Huaraz, las azucenas, las abejas. Estas últimas son bastante mencionadas en el relato, se dice que ellas saben la verdadera historia de la protagonista. Citamos la siguiente escena en donde se recurre a las abejas para saber con exactitud la historia de la santa.

Nada de lo que cuentan ciertos cantantes es verdad. Que me perdonen los señores cantantes si prefiero el testimonio de las abejas de Huaraz para contar y cantar la historia de Sarita Colonia y su familia alejándose de la santa tierra.

Así, desacreditando a sus colegas, comienza el canto de Juan Burro acerca de las célebres jornadas de la familia Colonia en su peregrinaje hacia Lima. (p. 65)

Pochi Marambio afirma que las abejas son personas muertas de Huaraz, incluida la familia de Sarita; incluso reconoce a la mamá de Sarita. Y es tan fantástica la escena que Pochi le pregunta al narrador oficial si es que él también las ve, a lo que este contesta que sí. José Antonio Bravo afirma: "en el realismo maravilloso la imaginación vuela y hace posible que lo real maravilloso viva con lo real objetivo en un mismo plano" (Bravo, 2011, p. 30). Esto es lo que está precisamente pasando en la conversación entre Pochi y el narrador. Leamos un fragmento de esta conversación. 
- No me gusta hablar de esto porque sé que no me crees, pero esas abejas son gente. Esas que están volando hacia el norte, esas que van y vienen de Huaraz. Tú no me lo vas a creer, pero son cristianos, son gente.

Pochi Marambio es quien lo dice. Otra vez narra un músico, pero este prefiere el rock, el jazz y otras melodías no muy cercanas al Burro ni al Embajador.

— ¿Estás viendo esa hilera de abejas?

- Las veo

- La que va adelante, esa que acaba de perderse entre los arbustos, esa es probablemente la madre de Sarita. Detrás de ella vienen otros difuntos siguiéndola. Son de Huaraz. Todo el tiempo van y vienen de allí. (p. 182)

El mencionado crítico añade: "en el realismo maravilloso los personajes tienen atributos superiores, realizan hechos extraordinarios, quienes los observan, creen, tienen fe" (Bravo, 2011, p. 30)7. En la novela, la protagonista tiene atributos superiores: ha resucitado después de treinta años de haber estado muerta, tiene poder para ayudar a los que le solicitan, a lo largo de la historia se lee los milagros que ella ha realizado en vida y después de haber resucitado, y por supuesto sus fieles tienen fe en todo esto. La escena que a continuación vamos a citar lo corrobora; sus devotos, cuando visitan su altar en el cementerio, además de pedirle que les haga algún milagro o agradecerle por el ya concedido, procuran llevar a sus casas agua mezclada con las flores que han depositado todos sus discípulos en las bandejas que se encuentran en el lugar porque están convencidos de que ese líquido les va a ayudar en sus diferentes tribulaciones cotidianas. Leamos:

Y los discípulos de Sarita, administradores del culto, tendrán tiempo también para ir arreglando las ofrendas florales sobre largas bandejas colmadas de agua en donde al cabo de los días las plantas depositarán sus esencias [...], que a su vez los devotos podrán llevar a sus casas en frascos y botellas porque su ingestión es buena para curar los dolores de estómago, para remediar la saladera, para limpiar de la mala suerte y de las penas guardadas, para aliviar los problemas del amor no correspondido, o tal vez para tragarse ese dolor de un solo sorbo. (p. 23)

La novela, tal como lo estamos demostrando, desde el inicio hasta el final presenta elementos propios del realismo maravilloso. José Antonio Bravo nos dice: "el realismo maravilloso sirve para dar testimonio o denunciar un estado de cosas, una situación, un evento, un hecho histórico" (Bravo, 2011, p. 117). 
En Sarita Colonia viene volando notamos que la novela denuncia al sistema capitalista, responsable de la violencia estructural. En el siguiente apartado desarrollaremos este tema.

\section{Representación de la subalternidad en Sarita Colonia viene volando}

Los fieles de Sarita Colonia son sujetos subalternos, seres "invisibles". En el desarrollo de las acciones se percibe que los devotos de la protagonista no están incluidos en el sistema hegemónico, están relegados y ellos son conscientes de su situación. De allí que se perciba que estos sujetos subalternos a través de sus historias de vida y milagros que le piden a la santa, articulan un discurso, no solamente con palabras, sino con acciones que desenmascara al sistema imperante y su poder opresivo ${ }^{8}$. En la escena que a continuación vamos a citar se percibe esta denuncia. Es tan miserable la existencia de estas personas que llegan a afirmar que el "calor" del infierno es más cálido que la realidad de la capital. Otro punto importante a destacar en la escena es que los fieles están más preocupados por sobrevivir, que estar pensando en la eternidad, y desde luego tienen mucha razón; pues resultaría ilusorio preocuparse por la gloria divina cuando aquí abajo hay temas más importantes de qué preocuparse: satisfacer el hambre, curar las enfermedades, buscar trabajo; en resumen, sobrevivir en este mundo. Leamos:

En otros milagros no creen los discípulos de Sarita Colonia. O más bien no creen en el milagro de los santos tradicionales. No les asombra que alguien vuele, converse con el Diablo o atraviese paredes. Ni el infierno ni la gloria son importantes para ellos, porque si existen, ocurren después de la muerte, y la gente prefiere morir para morir, y economizarse el resto. Las hogueras feroces que están reservadas para los pecadores deben ser por lo menos un poco más tibias que estos tristes suelos de Lima [...]. Y otros por fin insisten en que tal vez comenzarán a pensar en el tiempo perpetuo de allá arriba cuando aquí abajo se hayan acabado para siempre el frío, la miseria, la enfermedad, el olvido de Dios. (p. 26)

La subalternidad en el texto está dada por cuatro indicadores: económicos, sociales, culturales y religiosos. Los fieles son personas pobres, es más, el milagro que solicitan a la santa no es nada extraordinario, aunque para ellos sí lo sea. A saber: solicitan la ayuda de Sarita para aliviar alguna enfermedad, conseguir un puesto de trabajo y de esta forma tener un ingreso y poder satisfacer una necesidad básica: el hambre. Leamos la siguiente escena donde se evidencia lo que estamos afirmando.

Son centenares de páginas, pero no hay ni uno solo de esos milagros de antes: la gente tan solo da razón de sus escalofríos, de sus tercianas, de 
su falta de trabajo, de su necesidad de amor, y de cómo Sarita obró para lograr que un hombre, una mujer o una familia sobrevivieran en este mundo sin Dios. (p. 158)

Mario Suárez (1986) nos dice que Eduardo González Viaña perteneció al grupo Narración, el cual desarrolló una literatura comprometida con la sociedad, con el desarrollo de la urbe y que lamentablemente no ha sido valorada en toda su dimensión, él señala: "Su principal postulado: hacer una literatura popular, ideológica y con compromiso revolucionario sin que esto signifique, de ninguna manera, que el producto literario (la narración) pierda su calidad artística [...]. El valor de sus obras aún no ha sido reconocido en su verdadera dimensión" (Suárez, 1986, p. 10). En la novela se perciben estas características, tal como lo venimos demostrando, porque el ojo narrativo está enfocado en un sector marginal: los fieles de la santa. Socialmente, los devotos pertenecen a la clase media baja. Su cultura, si lo medimos con el termómetro del grupo de poder, es periférica, ninguneada por la cultura oficial ${ }^{9}$. La santa a la cual profesan fe no está inscrita oficialmente como tal en el canon religioso, en cambio la cultura oficial (hegemónica) tiene sus santos que sí son aceptados por la Iglesia. Es bastante ilustrativa la escena que a continuación mostramos. La ironía es magistral, Santa María Elena de los Aires, que también es tenida como santa por los pobres, le explica a Sarita que la Iglesia está "ocupada" para ponerles yeso a los "otros santos", que todavía conservan el apellido y el número de la libreta electoral. Leamos:

—Es que yo no sabía que los santos tuvieran apellido — tal vez replicó la hija de los Colonia.

-En que poca agua te ahogas, hijita. Bueno, la verdad es que todavía estás muy pequeña. Los santos oficiales claro que no llevan apellido, pero como tú comprenderás, ahora hay una gran cantidad de santos a los que la Iglesia todavía no ha tenido tiempo de ponerles yeso encima, $\mathrm{y}$ todos tienen nombres y apellidos, y hasta libretas electorales. (p. 70)

Romina Gatti (2009) nos dice que los fieles de Sarita Colonia son gente marginal, en consecuencia, sin poder. Sus argumentos son que estos marginales no poseen conocimiento académico y tampoco tienen poder económico para cambiar la dicotomía: ricos versus pobres. Es en ese sentido que la novela está dirigida hacia la gente de poder (intelectual y pudiente) y que Eduardo González Viaña no hace otra cosa que apelar a estos "poderosos" que cambien de actitud hacia estos marginales. Ella señala: "considero que es al sujeto ajeno al fenómeno de la pobreza al que va dirigida la novela [...] que es causante directa de la injusta dicotomía del mundo actual, o permite que esta se mantenga [...] su deseo, del autor, es incitarlos a cambiar su forma de accionar o adoptar una actitud activa condiciona al texto" (Gatti, 2009, p. 57). Es bastante ingenua la 
postura de Romina Gatti, pues jamás la condición del subalterno va a cambiar por voluntad del dominador, sino más bien por la propia acción del subalterno. En la novela se percibe claramente que los fieles no son ingenuos, no están de acuerdo con el orden del sistema capitalista, para nosotros el subalterno sí tiene poder. Es por ello que concordamos con Beverley (2004), quien afirma que el subalterno no está conforme con el discurso oficial y que la élite - y también los intelectuales - tienen miedo del sujeto subalterno, pues peligra su hegemonía.

Los personajes de la historia (subalternos) se dan cuenta de que en la sociedad no existe la homogeneidad social, económica y cultural, incluso religiosa. Pero lo interesante no es eso, pues es una realidad muy evidente; lo que suscita la atención es que tampoco creen en el discurso del Estado, a saber, que se interesa por ellos. Es decir, la ideología del poder no ha penetrado totalmente en sus mentes, porque es imposible, por más elaborada sea la ideología, que mediante un discurso tape tan deprimente realidad: desempleo, hambre, abuso, marginación ${ }^{10}$. Es por ello que los fieles recurren a la santa, a la intervención divina, con la esperanza que quizá el poder sobrenatural cambie su realidad. Ya están cansados de pedir auxilio al Estado, prefieren pedir ayuda a alguien que es igual a ellos: pobre, provinciana, marginada. El creyente pide una vida mejor, pide dignidad a su existencia. Una vez más la novela lo ejemplifica magistralmente, en la escena que vamos a citar. En ella se nota la identificación plena entre los fieles y la santa; pues se nos dice que Sarita no se la puede oficializar como santa porque es "pequeña" y no se la vería si la pusiéramos en un altar, y la razón es porque fue pobre, migrante; y los pobres han nacido para ser nadie en la sociedad. Leamos:

$\mathrm{Y}$ en ese momento, comienzo a entender a Sarita. Quizás la Iglesia nunca la proclame santa porque era pequeña de estatura, y no se la podría ver de pie en el altar o rezando en un altísimo cielo. Quizás se quede como vino al mundo, si de veras existió. Y si fue así nació para ser nadie, para ser como todos los hombres. Nació para ser nada, como terminan por serlo todos los pobres.(p. 196)

Antonio Cornejo Polar (1980) es bastante claro y enérgico al denunciar la intención del capitalismo, a saber, de querer eliminar nuestra identidad. Como sabemos, somos un país pluricultural y esto es precisamente nuestra esencia, nuestro ser; el capitalismo busca homogeneizar esta diversidad cultural. Cornejo señala: "Es claro que esta pluralidad de culturas está siendo afectada por la homogenización de un sistema capitalista moderno" (Cornejo, 1980, p. 297). Es en este contexto donde la literatura juega un rol muy importante, porque va a enfrentar esta amenaza, poniendo en evidencia que aquí en estas tierras no solo existe la cultura oficial, tradicional, sino también otras culturas. De allí que Antonio Cornejo Polar elogie a nuestro autor, porque su producción narrativa también aporta a evidenciar que existen otras literaturas y otras formas de hacer 
literatura, en consecuencia, otras culturas. Cornejo dice: "Esta veta literaria, por lo demás tan cercana al trabajo antropológico, se enriquece ahora abriendo otro frente con el último libro de González Viaña (1941). Autor de dos notables libros de cuentos (Los peces muertos, 1964; Batalla de Felipe en la casa de palomas, 1970)" (Cornejo, 1980, p. 297). Si bien es cierto esta valoración lo realiza el crítico literario centrando su atención en la novela ;Habla Sampedro: llama a los brujos! (1979); no obstante, estas ideas también son aplicables en nuestro objeto de estudio. La crítica social que se encuentra en el mundo representado de la novela va dirigida contra el sistema capitalista, de allí que la subalternidad debemos entenderla bajo la lógica de la ideología capitalista ${ }^{11}$. Los subalternos representados en el mundo posible de la obra nos muestran lo terrible que es el capitalismo y su presumida modernidad política, económica, científico-tecnológica y cultural: todo esto percibido en una sociedad burguesa. Es por ello, que la novela es muy interesante, porque interroga, cuestiona al capitalismo, y pone en evidencia lo que realmente es: imperialista y global. En consecuencia, no es casualidad que los devotos de la santa no se sientan identificados con el discurso oficial, que es la voz del capitalismo; pues este los margina, los invisibiliza y les pone el rótulo de ciudadanos de segunda clase: cuyas vidas pasan desapercibidas porque no son nadie en una sociedad burguesa. La escena, que a continuación vamos a citar, nos muestra seres que no tienen un rol protagónico en la sociedad, son forasteros en su propia sociedad: obreros, artesanos, limpiadores de carros, llenadores de micros, empleadas del hogar, etc. Leamos:

Igual se sentía Sarita, en medio de la tierra y del cielo, suspendida, sin peso, flotando por culpa de un milagro que acaso estaba haciendo el grupo reunido en el cementerio; rezando y desesperando, ellos le habían traído de vuelta, ellos: artesanos, obreros, vendedores de baratijas y de loterías, limpiadores de carros, llenadores de micros, servidoras domésticas, estudiantes de secretariado y de corte y confección, mariposas nocturnas, hombres, mujeres y hasta niños, desocupados, cercados, enfermos, sospechosos, ofendidos, violentos, avergonzados, hombres casi invisibles, hombres mínimos, hombres de nada, infelices a quienes el cielo también debe haber prohibido hacer milagros. (p. 19)

Queremos enfatizar, por lo que venimos desarrollando, que la ideología oficial no se ha apoderado por completo del imaginario del devoto de Sarita Colonia. Decimos esto porque una ideología cubre lo real, lo sustituye por una fantasía, pero esta logra su objetivo, afirma Žižek (1992), cuando el sujeto ya no opone ninguna resistencia entre ella y la realidad; es decir, cuando la ideología consigue determinar el modo de nuestra experiencia cotidiana de la realidad. Otro indicador que sirve para evidenciar que efectivamente una ideología ha triunfado, nos dice Žižek, es cuando incluso los hechos que a primera vista la contradecían empiezan a funcionar como argumentos a su favor. Esto que 
acabamos de explicar sobre la dominación ideológica no se da en los fieles de la santa. Ellos son conscientes de que son ciudadanos de segunda clase, de que no le importan al Estado, de que solo se tienen a sí mismos, y tal vez la ayuda de una santa, "si es que en verdad ha existido", tal como lo repiten los personajes a cada instante en sus quejas. En esta "duda" de los fieles queremos explicar dos ideas. Lo primero, tiene que ver con el grado de abandono por parte del Estado y la marginación que sufren ellos; su realidad es deprimente que no da signos de esperanzas de que algún día las cosas puedan mejorar. La desesperación en el mundo que viven, ya hasta a veces les hace dudar de la existencia de una santa que se parezca a ellos e interceda en el mejoramiento de su miseria. La segunda idea tiene que ver con los creyentes de la señorita ancashina, los cuales no son tan dados a la fe en Dios, sino más bien en una santa que se parece mucho a ellos. Esto se percibe con mucha frecuencia en sus oraciones, se "quejan" del abandono de Dios, y por ello piden a la santa que interceda, que comunique a Dios que en el mundo no solo existen los poderosos, también ellos.

\section{Conclusión}

Algunos críticos han cometido el error de asumir que Sarita Colonia viene volando es un texto biográfico o antropológico porque ha sido construido en base a los testimonios de Juan Burro, el Embajador de Quiquijana, Pochi Marambio, Hipólito Colonia y por testimonios de los fieles; en consecuencia, han realizado un análisis netamente sociológico, quitándole toda la complejidad ficcional que entraña la novela. La protagonista guarda relación con su prototipo real solamente por una reminiscencia lingüística. La semántica de los mundos posibles nos muestra que el material que procede del mundo real sufre una transformación sustancial en la frontera entre los dos mundos. En otras palabras, la Sarita Colonia que vivió en el mundo real tuvo una existencia típica, como la de cualquier ser humano pobre. Sin embargo, la Sarita Colonia de nuestra novela en estudio es totalmente distinta: tiene poderes sobrenaturales, conversa con Dios y le suceden cosas extraordinarias.

En la novela, desde el inicio hasta el final, estamos frente a un realismo maravilloso. La frontera entre la vida y la muerte se ha anulado, la protagonista resucita después de haber estado muerta treinta años. El paisaje, los lugares, los ambientes exteriores e interiores son extraños, remotos, misteriosos, exagerados. En Sarita Colonia viene volando la imaginación vuela y hace posible que lo real maravilloso viva junto con lo real objetivo en un mismo plano. Los personajes están sumergidos en un total realismo maravilloso, lo onírico fluyen. Presentimos la existencia de un cielo y un infierno, de una zona segura y una zona amenazante, pero no sabemos bien de qué lado estamos: todo es ambiguo, todo está medio vivo y medio muerto. 
Sin embargo, un texto literario no es netamente ficcional, trasciende la esfera estética. Sarita Colonia viene volando denuncia al sistema capitalista, responsable de la violencia estructural. El mundo representado de la novela pone en evidencia que la ideología oficial no se ha apoderado por completo del imaginario del devoto de la santa. Ellos son conscientes de que son ciudadanos de segunda clase, de que no le importan al Estado, de que solo se tienen a sí mismos, tal vez solo tienen la ayuda de una santa. Es, en este sentido, que los fieles, a través de sus historias y milagros que le solicitan a Sarita Colonia, articulan un discurso que desenmascara al poder hegemónico: injusto, excluyente, y opresivo. Esta reflexión nos permite entender por qué Sarita Colonia es un ícono de la subalternidad. Sus fieles son como ella: migrantes, ignorados por la sociedad capitalista. Pero, a pesar de todo, ellos no se amilanan y hacen sentir su presencia, su cultura, a través de Sarita Colonia. En otras palabras, la señorita ancashina va a legitimar la identidad del subalterno, una identidad distinta a la dada por el grupo de poder. Esto nos demuestra que el subalterno sí tiene el poder para hacer sentir su voz en una sociedad capitalista que pretende hacerlo invisible para siempre.

\section{Notas}

$1 \mathrm{El}$ presente artículo es parte de la investigación: Migración, subalternidad y violencia política en Sarita Colonia viene volando, que constituye el título de nuestra tesis de maestría.

2 Cuando un personaje ficcional comparte el mismo nombre que su prototipo real, Roland Barthes lo denomina "una forma lingüística de reminiscencia". Sin embargo, esto no significa que el personaje se comporte igual que su prototipo real. Lewis subraya que las cosas en mundos diferentes no son nunca idénticas, y conecta las varias encarnaciones de una misma cosa en mundos diferentes a través de la "relación de réplica". Rescher sugiere el término "versiones" para designar las diferentes "apariencias descriptivas" de "un mismo individuo" en mundos posibles diferentes (Cit. En Dolezel, 1999: 37).

3 Harshaw (1997) nos dice que los textos literarios construyen su propio Campo de Referencia Interno, al mismo tiempo que se refieren a él. Añade, también, que si los textos literarios constituyeran simplemente Campos de Referencia Internos, separados del mundo, podríamos llamarlos "ficciones" y limitar nuestro análisis a su estructura interna. Esto, sin embargo, no es toda la historia. Las obras literarias no son por lo general "mundos fictivos puros" y sus textos no están compuestos de meras preposiciones "fictivas" o de un lenguaje "fictivo" puro. Los significados dentro de los textos literarios se relacionan no solo con el Campo de Referencia Interno (el cual, en efecto, es privativo de los mismos), sino también con Campos de Referencia Externos. Esta naturaleza bipolar de la referencia literaria es un rasgo esencial de la literatura.

4 Carlos Franco (1990, mayo 21). "Sarita Colonia, o los cholos invaden el cielo: razones de un culto popular". E1 Comercio, p. 19- 20.

5 José Miguel Oviedo (1971) no analiza Sarita Colonia viene volando, su valoración lo realiza en el estudio de la obra Batalla de Felipe en la casa de palomas (1970). No obstante, sus reflexiones son aplicables para nuestra novela en estudio. 
6 Es fundamental precisar que las valoraciones de los críticos literarios que vamos a citar en el desarrollo de este tema: Ricardo González Vigil (1984), Luis Alberto Sánchez (1981), José Miguel Oviedo (1971), respecto a las técnicas narrativas de Eduardo González Viaña, lo hacen en base al análisis de Los peces muertos (1964), Batalla de Felipe en la casa de palomas (1973) e Identificación de David (1973); no obstante, las características del realismo maravilloso que ellos argumentan haber encontrado en estas obras, creemos son aplicables también a Sarita Colonia viene volando (1990.

7 Con respecto a las palabras milagro y fe, José Antonio Bravo nos advierte que la fe no se circunscribe únicamente en Dios, el término es bastante amplio. Por tanto, puede ser fe en un ser supremo, en el hombre, en sus posibilidades, en sus realizaciones, en su pasado, en su futuro. Por su parte, la palabra milagro tampoco debe ser entendida como un evento producido por un ser vinculado solo al cristianismo o a alguna otra religión. Su significado es mucho más vasto y se refiere a cualquier hecho extraordinario (Bravo, 2011, p. 29).

8 Spivak (2003) publicó su famoso ensayo “¿Puede hablar el subalterno?”, en 1985 su argumento central es que el subalterno no puede hablar. Nosotros no estamos de acuerdo con esta tesis. Desde luego, el sujeto subalterno no puede "hablar" en el lenguaje occidental (el lenguaje vencedor), pero sí a través del canto, el lenguaje del cuerpo y los sentimientos, tal como se percibe en los devotos de Sarita Colonia.

9 Nelly Richard (1996) demuestra que la división de "alta cultura" y "baja cultura" fue etablecida por los grupos hegemónicos, con el objetivo de legitimarse como los únicos productores de una verdadera cultura, y de esta manera dominar sobre los "otros" que no tienen el poder. Así mismo, Richard afirma que la universidad legitima el conocimiento, es decir, aquel conocimiento que no está en la universidad es un saber de segunda clase y hasta podría calificarse de un seudo saber.

10 Žižek (1992) nos dice que la ideología sirve para ocultar la verdad de las cosas, la ideología distorsiona la realidad, pero cuando nos damos cuenta de ese juego quiere decir que la ideología no se ha "apoderado" totalmente de nosotros.

11 Beverley (2004) expone acertadamente que la modernidad fue el objetivo a alcanzar tanto por el socialismo, como por el capitalismo. La polémica, la pugna residía en cuál de estos dos proyectos ideológicos era el más sofisticado, el más idóneo para alcanzar la modernidad política, económica, científico- tecnológica y cultural. El proyecto ganador, lo sabemos todos todos, fue el capitalismo. Es decir, su argumento: la fuerza del mercado libre y la privatización como vehículos para alcanzar la modernidad y el desarrollo económico convenció. La burguesía, obviamente, se decidió por el capitalismo, porque estaba más acorde a sus intereses: el respeto a la propiedad privada y el libre mercado.

\section{Referencias}

Andreu, A. (1999) Sarita Colonia viene volando de Eduardo González Viaña, una novela alternativa. En Jornadas Andinas de Literatura Latinoamericana (JALLA). Cusco: Fondo Editorial Cronolibros.

Beverley, J. (2004) Subalternidad, modernidad y multiculturalismo. Caracas: Nueva Sociedad.

Bravo, J. A. (2011) Lo real maravilloso en la narrativa latinoamericana (edición corregida y aumentada). Lima: Fondo Editorial Universidad Inca Garcilaso de la Vega. 
Cornejo Polar, A. (1980) Eduardo González Viaña: ¡Habla Sampedro: llama a los brujos! Revista de crítica literaria latinoamericana, 12 (6), 297-298.

Dolezel, L. (1999) Heterocósmica: ficción y mundos posibles. Madrid: Arco Libros.

Franco, C. (1990, mayo 21) Sarita Colonia, o los cholos invaden el cielo: razones de un culto popular. En El Comercio.

Gatti, R. (2009) Lo sagrado para los profanos: Sarita Colonia viene volando de Eduardo González Viaña (Tesis de Licenciatura). Pontificia Universidad Católica del Perú. Facultad de letras y Ciencias Humanas, Lima.

González Viaña, E. (1990) Sarita Colonia viene volando. Lima: Mosca Azul.

González Vigil, R. (1984) El cuento peruano (1957-1967). Lima: Copé.

Harshaw, B. (1997) Teorias de la ficción. Madrid: Taurus.

Iser, W. (1987) El acto de leer. Madrid: Taurus.

Oviedo, J. M. (1971) González Viaña, mitólogo. Amaru 14, 87-88

Richard, N. (1996) Signos culturales y mediaciones académicas. En B. González (compilador). Cultura y tercer mundo: Cambios en el saber académico. Caracas: Nueva Sociedad.

Sánchez, L. A. (1981) Derrotero para una bistoria cultural del Perú (Tomo V). Lima: Emi Editores.

Spivak, G. (2003) ¿Puede hablar el sujeto subalterno? Revista colombiana de antropología 30, 297-364.

Suárez, M. (1986) Veinte años que cuentan. Asalto al cielo 3, 10-12.

Žižek, S. (1992) El sublime objeto de la ideología. Madrid: Siglo Veintiuno. 
